\title{
Study on the Law of Membrane Efficiency of Unsaturated Shale and Its Application
}

\author{
Long Chang $\mathbb{D}^{1,2}$ Hongkui Ge $\mathbb{D}^{1,2,3}$ Yinghao Shen $\mathbb{D}^{1,2}$ Zehui Huang, ${ }^{1,2}$ and Qian Zhang ${ }^{1,2}$ \\ ${ }^{1}$ State Key Laboratory of Petroleum Resources and Prospecting, China University of Petroleum, Beijing 102249, China \\ ${ }^{2}$ Unconventional Natural Gas Institute, China University of Petroleum, Beijing 102249, China \\ ${ }^{3}$ China University of Petroleum-Beijing, Karamay 834000, China
}

Correspondence should be addressed to Hongkui Ge; gehongkui@163.com

Received 14 March 2018; Revised 25 May 2018; Accepted 4 July 2018; Published 25 July 2018

Academic Editor: Carmine Apollaro

Copyright (c) 2018 Long Chang et al. This is an open access article distributed under the Creative Commons Attribution License, which permits unrestricted use, distribution, and reproduction in any medium, provided the original work is properly cited.

The microscopic interaction mechanism between working fluids and shale reservoirs is the key basic issue for the efficient development of shale gas. The initial water saturation of clay-rich shale is low, and the water absorption through strong chemical osmosis is an important factor for the wellbore instability of the drilling fluid filtration loss and the low flowback rate of hydraulic fracturing. Membrane efficiency is a key parameter in evaluating the mechanical-chemical coupling of shale-fluid interaction. Because microcracks develop in reservoir shale, pressure transfer experiments are no longer capable of obtaining membrane efficiency value. In this paper, the characteristics of shale water saturation are considered. The model calculating membrane efficiency is obtained, and the shale membrane efficiency of the reservoir studied, based on the triple-layer model of clay mineral-water interface electrochemistry. Membrane efficiency of unsaturated shale depends on the excess charge density of the surface of the solid in different water saturations. The analysis of factors influencing shale membrane efficiency in unsaturated reservoirs shows that the shale membrane efficiency decreases with the increase of water saturation under unsaturated conditions. The partition coefficient of counterion in the Stern layer, cation exchange capacity, and solute concentration in pore fluid will affect the membrane efficiency of unsaturated shale. The membrane efficiency of the reservoir section shale in Fuling area is calculated and analyzed, and the water-absorbing capacity by chemical osmosis of the reservoir interval shale is evaluated based on the membrane efficiency model of unsaturated shale.

\section{Introduction}

Horizontal wells with long horizontal sections and staged fracturing technology are the key technologies for the successful development of shale gas. The engineering practice of shale gas drilling and production has found that phenomena such as drilling fluid filtration loss promote instable propagation of microcracks in boreholes within surrounding rock. Low backflow rates of hydraulic fracturing are widespread $[1,2]$. Compared with conventional oil and gas reservoirs, shale has low initial water saturation but large potential for water absorption. The dynamic force of shale reservoir imbibition working fluid mainly includes two aspects: (1) the development of micronanopores with strong capillary force and (2) strong mechanical-chemical coupling and interaction between working fluid and shale reservoirs due to high clay mineral content [3-5].

Chemical osmosis is a kind of infiltration driven by chemical gradients. Shale with semipermeable membrane properties is present in the concentration gradient, which will produce corresponding chemical osmotic pressure. The chemical osmotic problem in clay-rich shale is relevant to geophysics, environmental science, civil engineering, petroleum industry, and so forth.

Membrane efficiency is a key parameter in the study of mechanical-chemical coupling in the interaction between shale and fluid. Membrane efficiency represents the ability to restrain solute migration but allows solvent migration of a semipermeable membrane, defined as the ratio of hydraulic pressure caused by chemical osmosis to ideal osmotic pressure 
when balanced on both ends of a semipermeable membrane [6]. Shale is usually a nonideal semipermeable membrane, whose efficiency is between 0 and 1 . The value can be obtained by a pressure transfer experiment under different chemical potential (Cretaceous clay [7]; Wakkanai mudstones [8]; Ghom shale [9]).

A great deal of research has been carried out by related scholars on the microscopic mechanism of chemical osmosis and the experiment of coupling effects, and several theoretical models of membrane efficiency have been proposed [10]. According to the irreversible thermodynamic coupling flow theory, Katchalsky and Curran [11] considered that, under static conditions, thermodynamic force on the semipermeable membrane is in balance with the sum of mechanical friction forces produced by various components of solution in the membrane. Marine and Fritz [12,13] further developed the model and calculated the rules of the membrane efficiency of four types of clay minerals: montmorillonite, chlorite, illite, and kaolinite, varying with porosity in solutions with different concentrations of $\mathrm{NaCl}$. This model predicted that shale membrane efficiency would be higher at low porosity and high cation exchange capacities.

Based on the Gouy-Chapman diffuse double layer theory (DDL), Kemper and Rollins [14], Letey et al. [15], and Kemper and Quirk [16] superimposed ion exclusion factors in the water membrane thickness of clay particles. The theory proposes a theoretical model of membrane efficiency. It shows that the membrane efficiency under the action of the monovalent cation solution is higher than that of the divalent cation solution, and the membrane efficiency under the action of the divalent anion solution is higher than that of the monovalent anion solution. Based on this theory, Bresler [17] further found that membrane efficiency is related to the water membrane thickness and solution concentration of the clay particles, and that membrane efficiency decreases with the increase of the product of the water membrane thickness and the square root of the solution concentration. Bader [18] summarized the model and produced a calculation formula. By using the Bresler membrane efficiency model, the membrane efficiency of Pierre Shale [19, 20], Ponza bentonite and Bisaccia clay [21], Boom clay [22], and CallovoOxfordian clay [23] was studied.

Neither Marine and Fritz's model nor Kemper and Bresler's model, can directly characterize the influence of water saturation on the membrane efficiency of unsaturated porous media. Aiming at the electrokinetic problem of clay-rich porous media, Leroy and Revil [24] proposed a triple-layer model (TLM) that describes the electrochemical properties of clay minerals. By using this model, the charged triple-layer structure of Stern and diffuse layers in clay-water interfaces was analyzed: the calculated results of $\zeta$ potential and low-frequency (few $\mathrm{kHz}$ ) surface conductivity show that the structure has good applicability to the $1: 1$ type (kaolinite) and 2:1 type (montmorillonite) of clay minerals. Using the triple-layer theory, Revil et al. [25] and Gonçalvès et al. [26] studied the multifield coupling flow regularity of clay-rich porous media fluid. The computational model of membrane efficiency was obtained and applied in aspects such as ion diffusion of Callovo-Oxfordian argillite, fluid migration, and electrokinetic coupling. Concerning water saturation, the model is also applicable to unsaturated porous rocks $[27,28]$.

Based on the triple-layer model of clay-water interfaces established by Leroy and Revil [24], a computational model of unsaturated shale membrane efficiency is established in this paper by using the coupling constitutive equations of heterogeneous porous media. Taking water saturation into account, the change law of the membrane efficiency of clayrich porous media is analyzed by numerical calculation. Finally, the theory is applied to predict the membrane efficiency of reservoir shale in Fuling area. The distribution law of the membrane efficiency under initial watersaturated condition is obtained, and the water-absorbing capacity by chemical osmosis of per unit pore of the shale in the reservoir section is evaluated.

\section{Electrochemical Properties of a Clay-Water Interface}

The semipermeable membrane property of shale can be attributed to the charged structure on the surface of clay mineral. Clay platelets are close to each other in low aperture shale, and electrical fields overlap while charged ions are blocked in this channel. At this moment, the channel will act as a semipermeable membrane effectively (Figure 1(a)). However, if the two clay platelets are far apart, and their electrical fields do not overlap (Figure 1(b)), then ions can pass through the channel freely. The clay particle act as a nonideal semipermeable membrane [29, 30].

The surface of a shale clay mineral has negative charge, attracts the counterions (cations) in the liquid phase in the shale pore, and repels the electrostatic of the same sign ion. At low water saturations, the counterions are packed in a smaller volume and therefore the effective excess charge density of the pore water is relatively high. At high water saturations, the excess charge density of the pore water is relatively low, such as illustrated in Figure 2. Membrane efficiency of unsaturated shale depends on the excess charge density of the surface of the solid in different water saturations.

A triple layer structure with the opposite sign and equal amount of charge appears on both sides of the solid-liquid interface. As shown in Figure 3, the layers of the clay mineral-water interface are as follows: the inner Helmholtz layer (IHP), the outer Helmholtz layer (OHP), and the diffuse layer. The IHP and OHP form the Stern layer, which firmly adheres to the solid surface. In the event of an electrokinetic phenomenon, the Stern layer moves with the solid particles and causes relative sliding within the diffuse layer. The interface between the Stern layer and the diffuse layer is called the shear plane. The potential difference between the shear plane and the solution body is called $\zeta$ potential. The magnitude of $\zeta$ potential reflects the degree of charge within the solid particles.

The porous shale is saturated by two immiscible phases, with one wetting phase for the solid phase and one nonwetting phase. The pore water comprises the water molecules, 


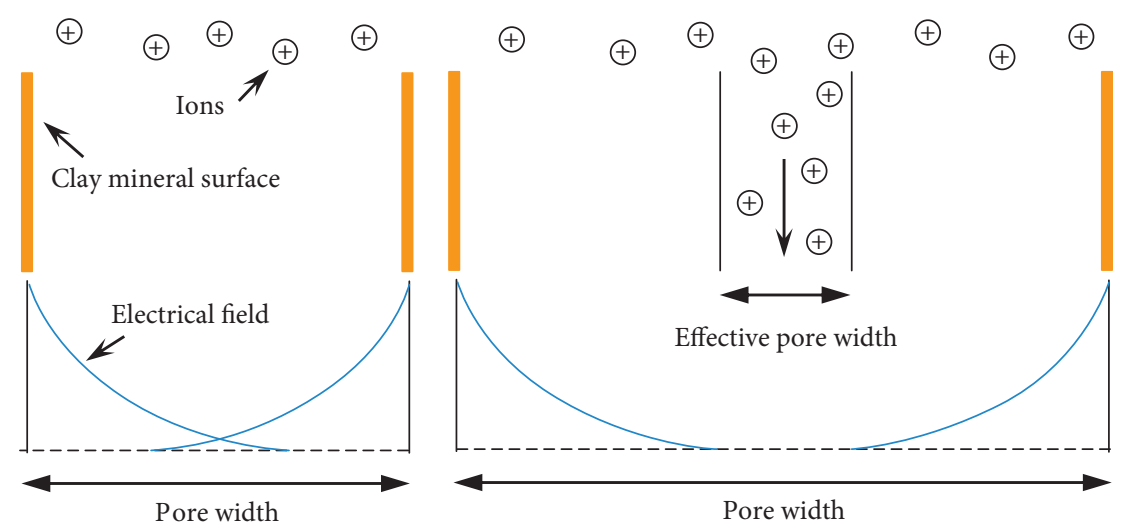

(a) Ideal semipermeable membrane

(b) Nonideal semipermeable membrane

Figure 1: Clay as semipermeable membrane.

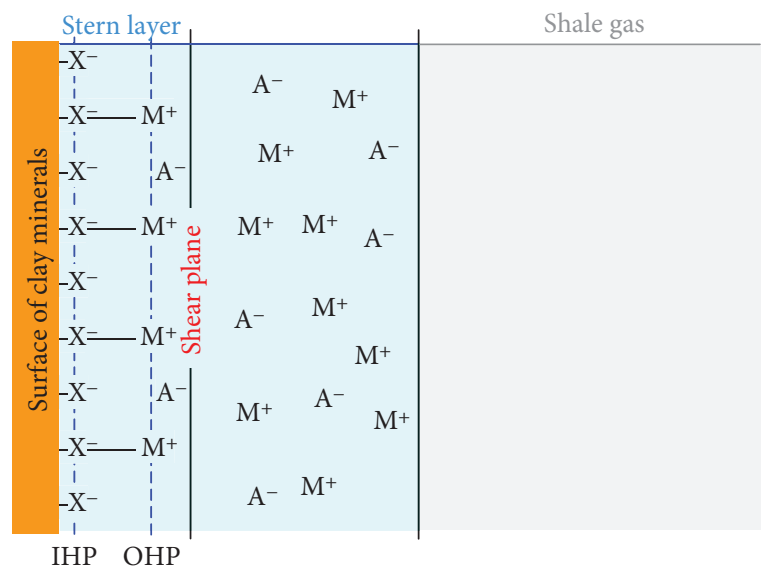

(a)

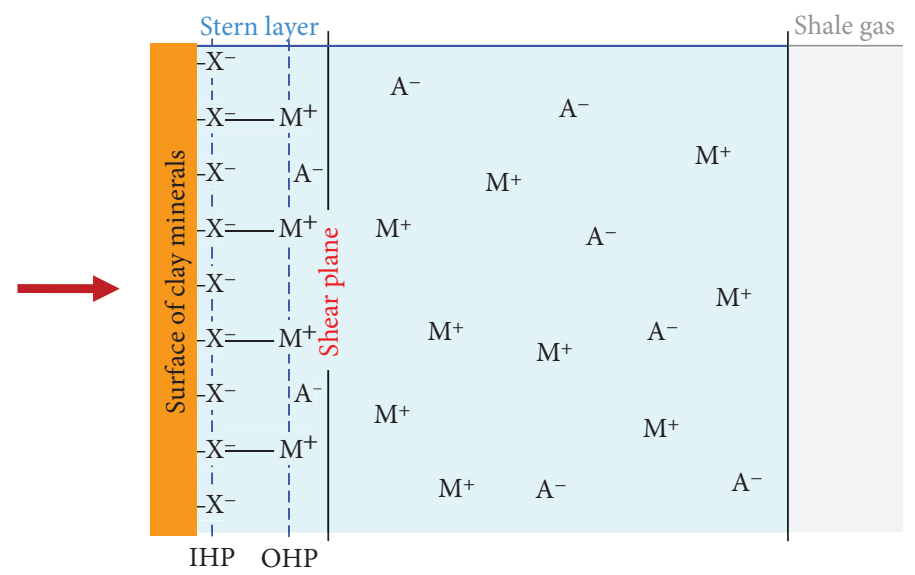

(b)

FIGURE 2: Sketch of the excess charge density of the pore water in different water saturations.

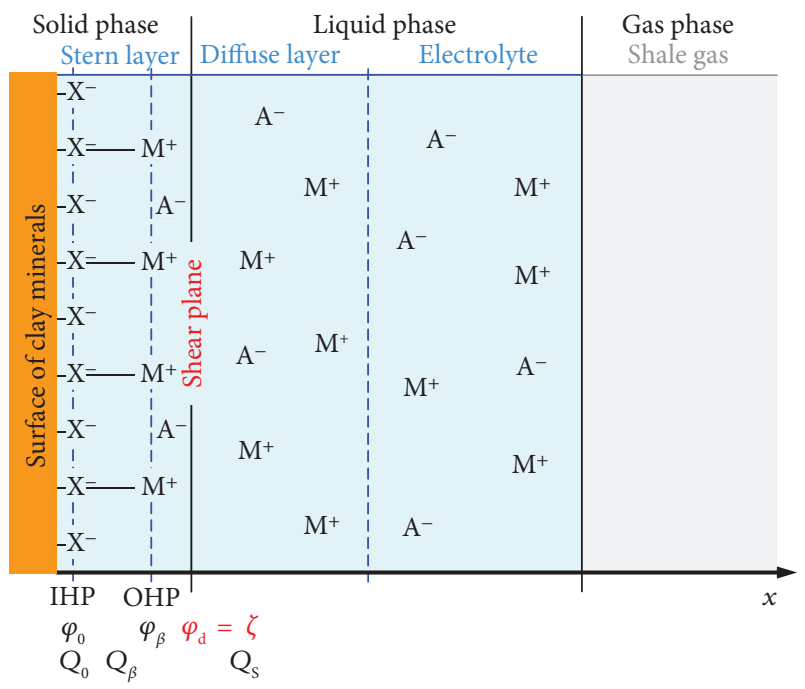

FIGURE 3: Sketch of triple-layer model of the clay-water interface. plus solute species and the nonwetting phase is shale gas. In the reference state, the water saturation is defined by

$$
s_{\mathrm{w}}=\frac{\theta}{\phi}
$$

where $\theta$ is the water content (volume fraction); $\phi$ is connected porosity.

We denote by $S_{\mathrm{sw}}$ the contact area between the shale solid phase and the wetting phase and by $S_{n w}$ the contact area between the nonwetting phase and the wetting phase. $Q_{0}$ represents the charge density of the surface minerals; $Q_{\beta}$ represents the charge density of the Stern layer; finally, $Q_{S}$ represents the charge density of the diffuse layer [26].

$$
Q_{\mathrm{S}}=Q_{0}+Q_{\beta}
$$

Ignoring the gas/water interface charge, the porous shale electrical balance equation is

$$
\bar{Q}_{\mathrm{V}}^{0}+\frac{S_{\mathrm{sw}}}{V_{\mathrm{w}}} Q_{\mathrm{S}}=0
$$


where $V_{\mathrm{w}}$ is the volume of pore water in the representative elementary volume (REV), $\mathrm{m}^{3} ; \bar{Q}_{\mathrm{V}}^{0}$ is the volume charge density of the pore space in fully saturated rock, $\mathrm{C} / \mathrm{m}^{3}$. Under unsaturated conditions, when the water saturation is $s_{\mathrm{w}}$, the effective charge density $\bar{Q}_{V}$ is

$$
\bar{Q}_{\mathrm{V}}=\frac{\bar{Q}_{\mathrm{V}}^{0}}{s_{\mathrm{w}}} .
$$

Under saturated conditions, the total charge density of counterion per unit pore volume $Q_{V}^{0}\left(\mathrm{C} / \mathrm{m}^{3}\right)$ is

$$
Q_{\mathrm{V}}^{0}=\rho_{\mathrm{g}} \frac{1-\phi}{\phi} \mathrm{CEC}
$$

where $\rho_{\mathrm{g}}$ is the grain density of shale, $\mathrm{kg} / \mathrm{m}^{3}$; CEC is cation exchange capacity, meq/g.

The volume charge density of counterion in rock pore space is

$$
\bar{Q}_{\mathrm{V}}^{0}=\left(1-f_{\mathrm{Q}}\right) Q_{\mathrm{V}}^{0},
$$

where $f_{\mathrm{Q}}$ is the distribution coefficient and represents the distribution ratio of counterion in the Stern layer.

$$
f_{\mathrm{Q}}=\frac{\sum_{i=1}^{Q} z_{i} \Gamma_{\mathrm{X}_{i} \mathrm{M}}^{0}}{\sum_{i=1}^{Q} z_{i} \Gamma_{\mathrm{X}_{i} \mathrm{M}}^{0}+\sum_{i=1}^{Q} z_{i} \Gamma_{\mathrm{X}_{i} \mathrm{M}}^{S}},
$$

where $\Gamma_{\mathrm{X}_{i} \mathrm{M}}^{0}$ and $\Gamma_{\mathrm{X}_{i} \mathrm{M}}^{S}$ are, respectively, the surface position densities of counterion absorbed in the Stern layer and diffuse layer; $Q$ is the type number of counterion in the electrolyte, $z$ is the valence.

\section{Membrane Efficiency of Unsaturation Porous Media}

In isothermal conditions, the macroscopic flux of the salt, $\mathbf{J}_{\mathrm{s}}$, the macroscopic current density, $\mathbf{J}_{c}$, and the Darcy velocity, $\mathbf{J}_{\mathrm{f}}$, are all cross-coupled macroscopic fluxes. These fluxes are all dependent on thermodynamic forces, taken here as the gradients of the thermodynamics potentials. They are the chemical potential of the salt, $\mu_{\mathrm{f}}$, the electrical potential, $\psi$, and the effective pore fluid pressure, $\bar{p}[25]$.

$$
\begin{aligned}
{\left[\begin{array}{c}
2 \mathbf{J}_{\mathrm{s}}-\left(\bar{C}_{+}+\bar{C}_{-}\right) \mathbf{J}_{\mathrm{f}} \\
\mathbf{J}_{\mathrm{c}}-\bar{Q}_{\mathrm{V}} \mathbf{J}_{\mathrm{f}} \\
\mathbf{J}_{\mathrm{f}}
\end{array}\right]=} & -\left[\begin{array}{ccc}
\frac{\sigma_{\mathrm{e}}}{e^{2}} & \frac{1}{e}\left(\sigma_{\mathrm{e}}^{+}-\sigma_{\mathrm{e}}^{-}\right) & 0 \\
\frac{1}{e}\left(\sigma_{\mathrm{e}}^{+}-\sigma_{\mathrm{e}}^{-}\right) & \sigma_{\mathrm{e}} & 0 \\
\frac{k}{\eta_{\mathrm{f}}}\left(\bar{C}_{+}+\bar{C}_{-}\right) & \frac{k}{\eta_{\mathrm{f}}} \bar{Q}_{\mathrm{V}} & \frac{k}{\eta_{\mathrm{f}}}
\end{array}\right] \\
& \cdot\left[\begin{array}{c}
\nabla \mu_{\mathrm{f}} \\
\nabla \psi \\
\nabla \bar{p}
\end{array}\right] .
\end{aligned}
$$

The chemical potential gradient and osmotic pressure gradient are, respectively,

$$
\begin{gathered}
\nabla \mu_{\mathrm{f}}=k_{\mathrm{B}} T \nabla \ln C_{\mathrm{f}}, \\
\nabla \pi=2 k_{\mathrm{B}} T \nabla C_{\mathrm{f}} .
\end{gathered}
$$

There is a relationship between the chemical potential gradient and osmotic pressure gradient:

$$
\nabla \mu_{\mathrm{f}}=\nabla \frac{\pi}{2} C_{\mathrm{f}} .
$$

By coupling the flow constitutive equation, the influence of flow potential on total current density is neglected:

$$
\mathbf{J}_{\mathrm{c}}=-\frac{1}{e}\left(\sigma_{\mathrm{e}}^{+}-\sigma_{\mathrm{e}}^{-}\right) \nabla \mu_{\mathrm{f}}-\sigma_{\mathrm{e}} \nabla \psi .
$$

Additionally,

$$
T_{\mathrm{e}}^{+}=\frac{\sigma_{\mathrm{e}}^{+}}{\sigma_{\mathrm{e}}}=1-T_{\mathrm{e}}^{-} .
$$

$T_{\mathrm{e}}^{+}$is the Hittorf number of the cation:

$$
T_{\mathrm{e}}^{+}=\frac{\beta_{+}\left(\sqrt{1+R^{2}}+R\right)}{\beta_{+}\left(\sqrt{1+R^{2}}+R\right)+\beta_{-}\left(\sqrt{1+R^{2}}-R\right)},
$$

where $\beta_{ \pm}$are the mobilities of anion and cation in water, $\mathrm{m}^{2} / \mathrm{s} \cdot \mathrm{V}$.

There is

$$
\left.\nabla \psi\right|_{\mathrm{J}_{\mathrm{c}}=0}=\frac{1}{e}\left(1-2 T_{\mathrm{e}}^{+}\right) \nabla \mu_{\mathrm{f}}=\frac{1}{e}\left(1-2 T_{\mathrm{e}}^{+}\right) \nabla \frac{\pi}{2} C_{\mathrm{f}} .
$$

By

$$
\begin{gathered}
\bar{p}=p-\pi, \\
\bar{C}_{+}+\bar{C}_{-}=2 C_{\mathrm{f}} \sqrt{1+R^{2}}, \\
R=\frac{\bar{Q}_{\mathrm{V}}}{2 e C_{\mathrm{f}}} .
\end{gathered}
$$

Additionally, the Darcy velocity in constitutive equation is

$$
\mathbf{J}_{\mathrm{f}}=-\frac{k}{\eta_{f}}\left[\left(\bar{C}_{+}+\bar{C}_{-}\right) \nabla \mu_{\mathrm{f}}+\bar{Q}_{\mathrm{V}} \nabla \psi+\nabla \bar{p}\right],
$$

and becomes

$$
\mathbf{J}_{\mathrm{f}}=-\frac{k}{\eta_{\mathrm{f}}}\left[\sqrt{1+R^{2}} \nabla \pi+R\left(1-2 T_{\mathrm{e}}^{+}\right) \nabla \pi+\nabla p-\nabla \pi\right] .
$$


TABLE 1: Analysis parameters of membrane efficiency.

\begin{tabular}{lcc}
\hline Parameters & Value & Units \\
\hline$e$ & $1.6 \times 10^{-19}$ & $\mathrm{C}$ \\
$\beta_{+}$ & $5.19 \times 10^{-8}$ & $\mathrm{~m}^{2} \cdot \mathrm{s}^{-1} \cdot \mathrm{V}^{-1}$ \\
$\beta_{-}$ & $7.91 \times 10^{-8}$ & $\mathrm{~m}^{2} \cdot \mathrm{s}^{-1} \cdot \mathrm{V}^{-1}$ \\
$\rho_{\mathrm{g}}$ & 2655 & $\mathrm{~kg} \cdot \mathrm{m}^{-3}$ \\
$\phi$ & 4.2 & $\%$ \\
$f_{\mathrm{Q}}$ & 0.94 & - \\
$\mathrm{CEC}$ & 0.07 & $\mathrm{meq} \cdot \mathrm{g}^{-1}$ \\
$C_{\mathrm{f}}$ & 0.10 & $\mathrm{~mol} \cdot \mathrm{L}^{-1}$ \\
\hline
\end{tabular}

Note: The mobilities of ions in water is $298 \mathrm{~K} \mathrm{NaCl}$ aqueous solution.

According to the definition of membrane efficiency of chemical osmosis,

$$
\begin{aligned}
& \mathbf{J}_{\mathrm{f}}=-\frac{k}{\eta_{\mathrm{f}}}[\nabla p-\sigma \nabla \pi], \\
& \sigma \equiv\left(\frac{\Delta p}{\Delta \pi}\right)_{\mathbf{J}_{\mathrm{f}}=0} .
\end{aligned}
$$

Contrasting (18), the membrane efficiency expression of unsaturated porous media can be obtained as follows:

$$
\sigma=1-\sqrt{1+R^{2}}-R\left(1-2 T_{\mathrm{e}}^{+}\right) .
$$

\section{Sensitivity Study}

The physical and chemical parameters related to the shale of organic-rich reservoirs are substituted into the above formula, and the variables are controlled appropriately. Then, the change laws of the counterion partition coefficients of the Stern layer, as well as the cation exchange capacity and the shale membrane efficiency under the influence of the solute concentration in pore fluid, are obtained under unsaturated conditions. The relevant data used in the calculation are shown in Table 1.

4.1. Partition Coefficient of Counterion in the Stern Layer. By (10), the partition coefficient $f_{\mathrm{Q}}$ is defined as the surface concentration of counterions in the Stern layer, divided by the total surface concentration of counterions in both the diffuse layer and the Stern layer. By using the triple-layer model, Leroy and Revil [31] calculated and obtained that the pure clay mineral kaolinite $f_{\mathrm{Q}}$ is 0.98 , illite $f_{\mathrm{Q}}$ is 0.90 , and smectite $f_{\mathrm{Q}}$ is 0.85 . Revil [32] analyzed the electrical double-layer structure of argillaceous sandstone and obtained that $f_{\mathrm{Q}}$ is from 0.89 to 0.99 . With high solute concentration in pore fluid, the charged layer is compressed, and the specific gravity of the counterion in the Stern layer is larger. The value of $f_{\mathrm{Q}}$ ranges from 0.90 to 0.98 for sensitivity analysis of the parameter in this paper.

The calculated results of membrane efficiency varying with water saturation under different partition coefficients are shown in Figure 4(a). The membrane efficiency decreases with the increase of water saturation when the partition coefficients are different. The partition coefficient of counterion in Stern layer approaches 1, and the membrane efficiency approaches 0 when under full-saturated conditions. At this time, shale cannot act as a semipermeable membrane. The membrane efficiency decreases at different rates while water saturation increases. When the water saturation increases to $60 \%$, the reduction of membrane efficiency decreases. The larger the partition coefficient is, the larger the reduction of membrane efficiency is. As shown in Figure 4(b), for shale with different water saturation, the membrane efficiency decreases with the increase of partition coefficient; if the partition coefficient is greater than 0.96 , the reduction of shale membrane efficiency, varying with the increase of partition coefficient, is larger with different levels of water saturation.

4.2. Cation Exchange Capacity (CEC). The CEC represents the capacity of a porous material to exchange cations between the mineral surface and the solution in pore fluid. According to the clay mineral content and composition of reservoir shale, sensitivity analysis of cation exchange capacities in the range of $0.03-0.13 \mathrm{meq} / \mathrm{g}$ was carried out, with the curve of membrane efficiency varying with water saturation under different CECs and the curve of membrane efficiency varying with CEC under different water saturation. The results are shown, respectively, in Figure 5.

With a different cation exchange capacity, the trend of membrane efficiency decreasing with the increase of water saturation is different. The membrane efficiency of low CEC shale further decreases with the increase of water content, and the membrane efficiency is lower under saturated conditions. Too low of a cation exchange capacity will render the shale ineffective as a semipermeable membrane, and higher cation exchange capacity of the shale corresponds with higher membrane efficiency under full saturated conditions. This conclusion is consistent with the research results of Marine and Fritz [12]. Under different water-saturation conditions, the membrane efficiency will increase with the increase of CEC and will change from rapid increase to a gentle increase. Shale membrane efficiency is higher with low water saturation and high cation exchange capacity.

4.3. Solute Concentration in Pore Fluid. Fluid salinity is high in marine sedimentary shale formations. The study of the effect of solute concentration in pore fluid on shale membrane efficiency under unsaturated conditions is conducted in the range of $0.02 \sim 0.27 \mathrm{~mol} / \mathrm{L}$. As shown in Figure 6, the membrane efficiency decreases with the increase of water saturation under different solute concentrations in pore fluid. Under full saturated conditions, the solute concentration in pore fluid of shale acting as a semipermeable membrane grows higher as membrane efficiency grows lower. This conclusion agrees with the research of Bresler [17] and Bader [18] in their study of membrane efficiency and solution concentration. Under unsaturated conditions, shale membrane efficiency also decreases with the increase of solute concentration in pore fluid. As solute concentration increases, the reduction rate of membrane efficiency is initially quick but later becomes slow. It eventually tends to gentle decline. 


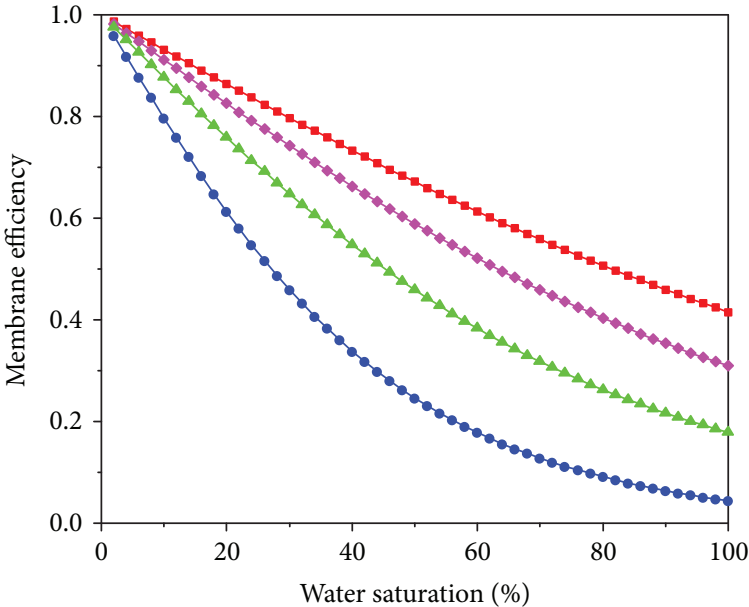

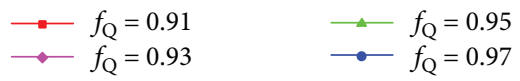

(a) The membrane efficiency changes with the water saturation under different partition coefficients

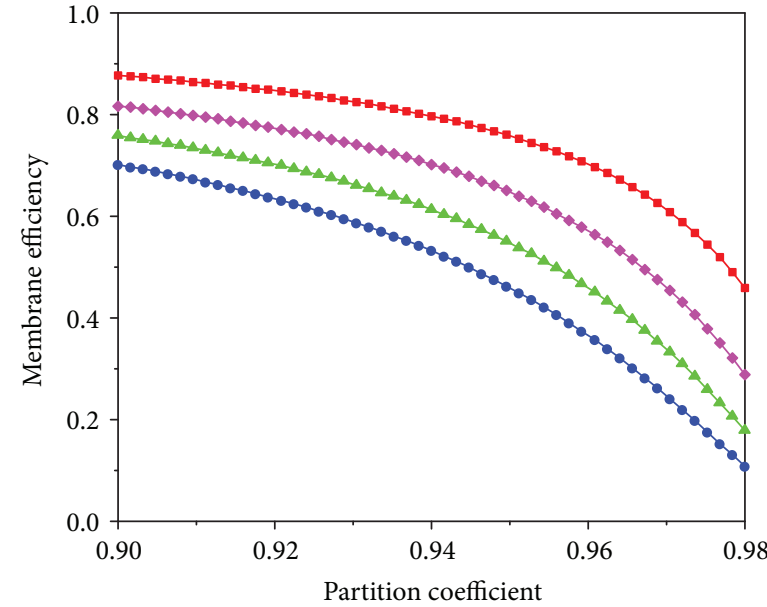

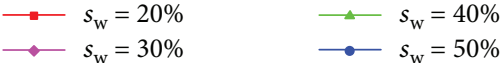

(b) The membrane efficiency changes with the partition coefficient under different water saturation

FIGURE 4: Effect of partition coefficient on membrane efficiency under unsaturated conditions.

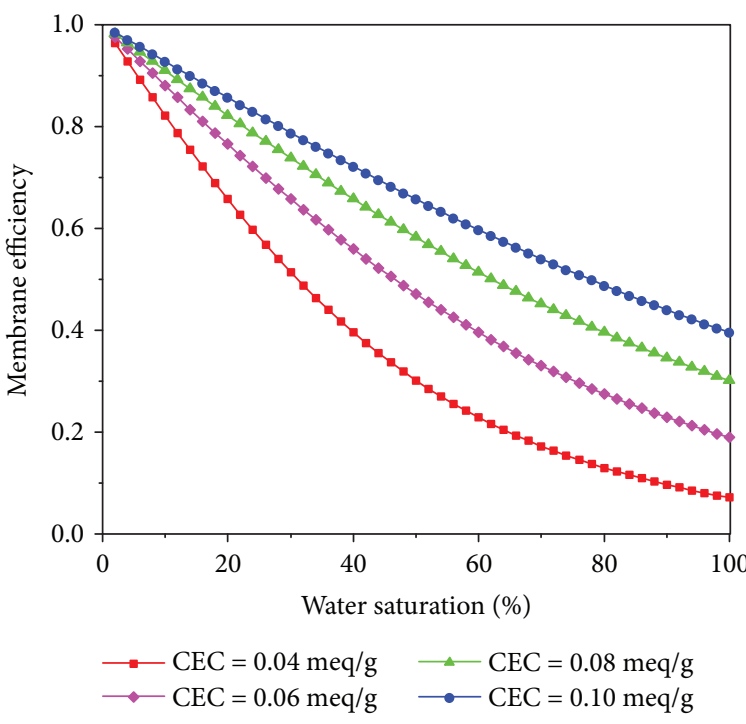

(a) The membrane efficiency changes with the water saturation under different CEC

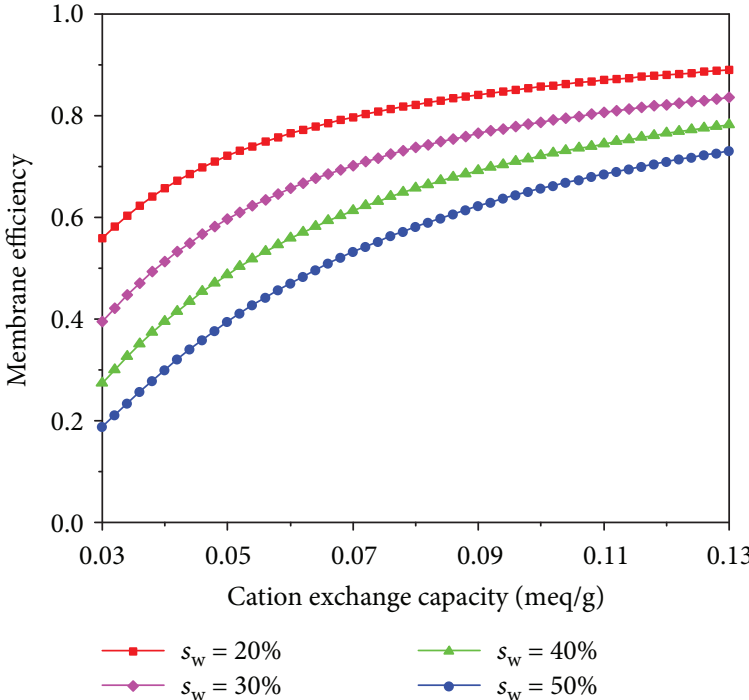

(b) The membrane efficiency changes with the CEC under different water saturation

FIGURE 5: Effect of cation exchange capacity on membrane efficiency under unsaturated conditions.

\section{Application}

Membrane efficiency of Fuling shale was analyzed by using the abovementioned unsaturated porous membrane efficiency model, which in consequence evaluated the water-absorbing capacity by chemical osmosis of the shale.

5.1. The Cation Exchange Capacity of Reservoir Shale. Through experiments with five reservoir shale samples in the Fuling area, the cation exchange capacity of shale was determined to be $0.058 \sim 0.094 \mathrm{meq} / \mathrm{g}$, and the value of specific surface area is between 16 and $28 \mathrm{~m}^{2} / \mathrm{g}$. The experimental results is close to the research of Fuling shale obtained by $\operatorname{Lin}$ et al. [33]. In contrast with the cation exchange capacity of different single clay minerals and argillaceous sandstone [34], the cation exchange capacity of Fuling shale is low, as shown in Figure 7.

The experimental results of rock core, whole-rock mineral content in the reservoir interval, show that the content of clay minerals is $17.5 \% \sim 59 \%$ with an average of $38.26 \%$, which 


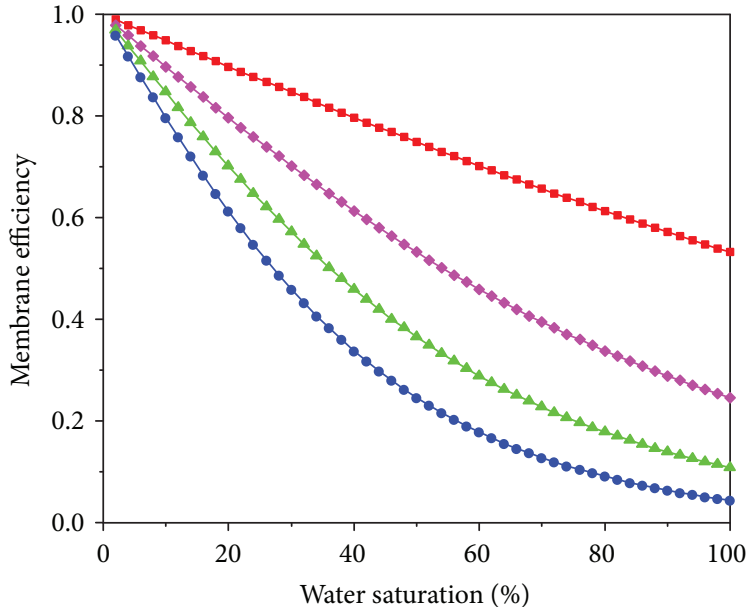

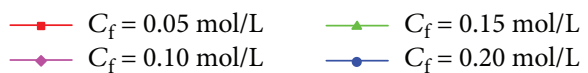

(a) The membrane efficiency changes with water saturation under different solute concentrations

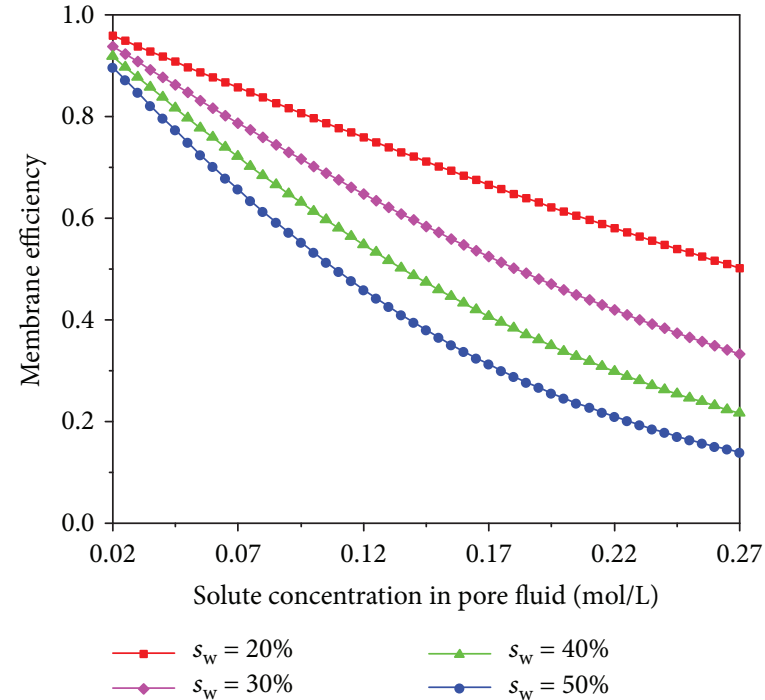

(b) The membrane efficiency changes with the solute concentration under different water saturation conditions

FIGURE 6: Effect of solute concentration in pore fluid on membrane efficiency under unsaturated conditions.

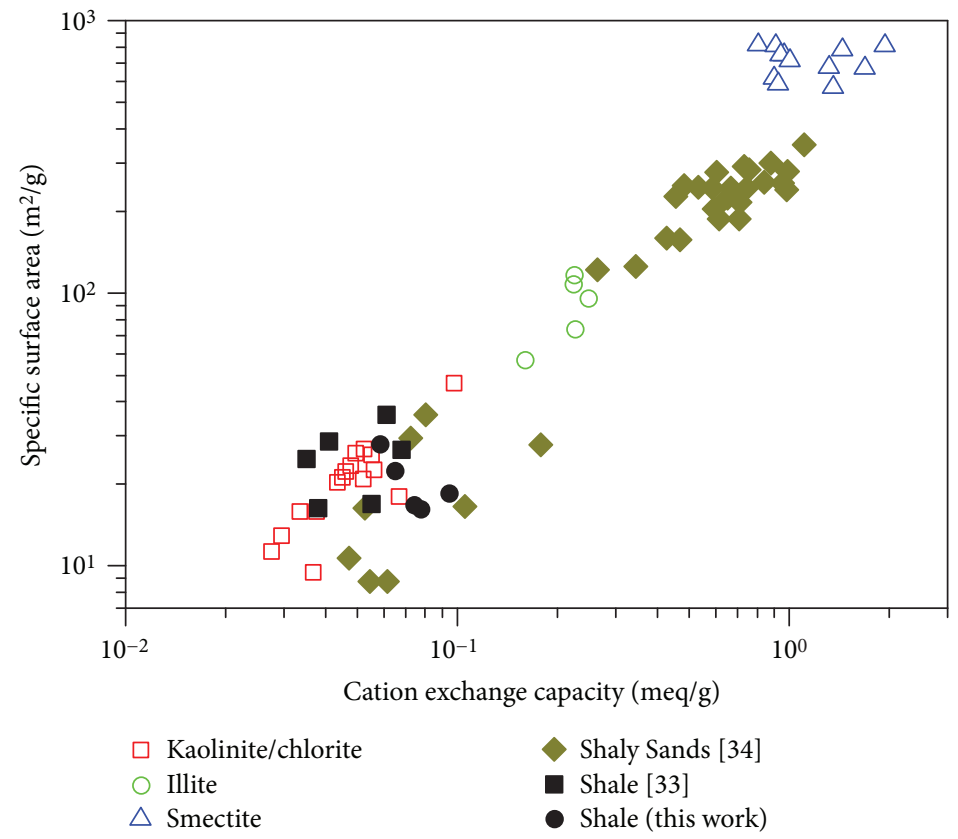

Figure 7: Relationship between specific surface area and cation exchange capacity.

shows an upward trend from bottom to top. The clay minerals mainly include mixed layer minerals of illite/smectite and illite, followed by chlorite (Figure 8). The ratio of illite/smectite in mixed-layer minerals is $10 \%$. The low cation exchange capacity of the major clay minerals is responsible for the low cation exchange capacity of the Fuling shale.

Aiming at the reservoir shale containing multicomponent clay minerals in the whole well, its cation exchange capacity is determined by the clay mineral content of each component and the cation exchange capacity of a single mineral [35].

$$
\mathrm{CEC}=\chi_{\mathrm{I}} \mathrm{CEC}_{\mathrm{I}}+\chi_{\mathrm{C}} \mathrm{CEC}_{\mathrm{C}}+\chi_{\mathrm{S}} \mathrm{CEC}_{\mathrm{S}}
$$

where $\chi_{i}$ and $\mathrm{CEC}_{i}$ are, respectively, the mass fraction of the clay mineral component $i$ and the cation exchange capacity, the subscripts I, C, and S, respectively, represent illite, chlorite, and smectite. 


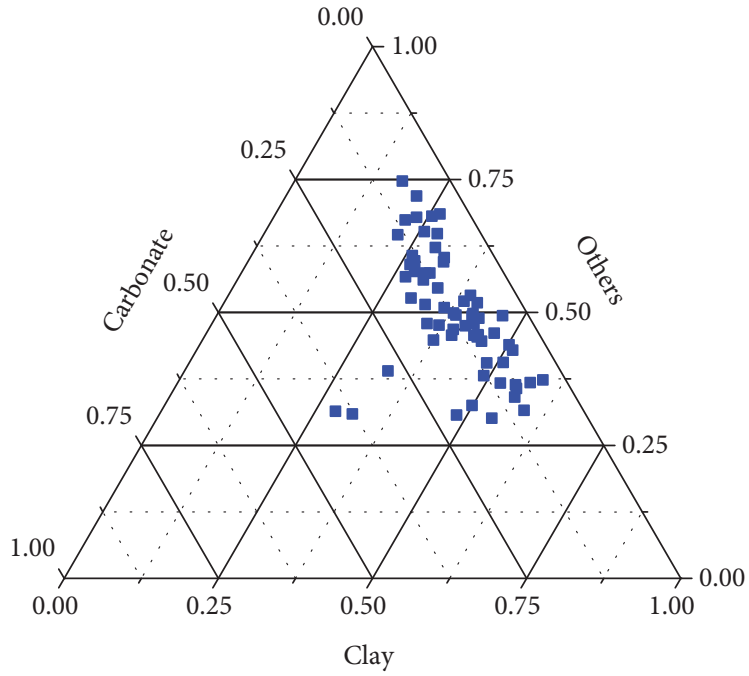

(a) Whole-rock mineral content

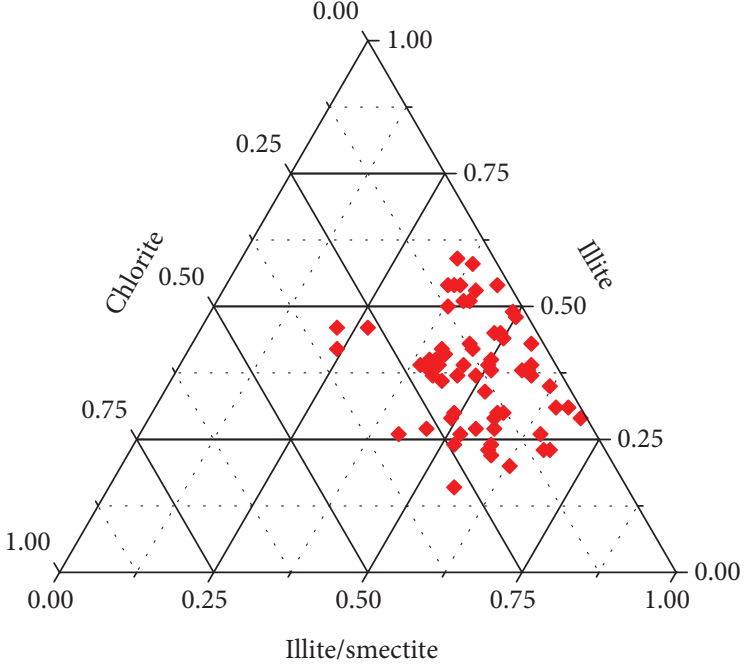

(b) Clay minerals content

FIGURE 8: The characteristics of reservoir shale mineral composition.

TABLE 2: Cation exchange capacity of different clay minerals.

\begin{tabular}{lcc}
\hline Clay minerals & CEC $(\mathrm{meq} / \mathrm{g})$ & Reference value $(\mathrm{meq} / \mathrm{g})$ \\
\hline Smectite & 1.00 & $0.80 \sim 1.50$ \\
Illite & 0.25 & $0.10 \sim 0.40$ \\
Chlorite & 0.15 & $0.10 \sim 0.40$ \\
\hline
\end{tabular}

According to the reference range for the cation exchange capacity of each clay mineral, the shale clay mineral content and measured shale cation exchange capacity were fitted to determine the CEC calculated values of the three clay minerals, as shown in Table 2.

In Figure 9, the distribution results of clay mineral content show reservoir interval shale and CEC varying with depth. As the depth of the well increases, the total amount of clay minerals decreases. The contents of three types of clay minerals thus decrease in turn. The shale cation exchange capacity is mainly in the range of $0.06 \sim 0.12 \mathrm{meq} / \mathrm{g}$, decreasing with the increase of well depth.

5.2. The Membrane Efficiency of Reservoir Shale. Parameters such as reservoir interval core porosity and initial water saturation are used as they are substituted into the shale membrane efficiency model. Additionally, the vertical distribution of shale membrane efficiency under the original formation condition is calculated and obtained, which is used to characterize the water-absorbing capacity by chemical osmosis.

The calculating parameters and results regarding reservoir shale are shown in Figure 9. Shale grain density ranges from 2581 to $2790 \mathrm{~kg} / \mathrm{m}^{3}$, decreasing with the increase of well depth. The porosity of reservoir shale is mainly in the range of $3 \%$ 5\%; the minimum value is $1.95 \%$, and the maximum value is $5.27 \%$. The overall trend is as follows: the shale porosity increases as well depth decreases. Initial water saturation of cores is measured in the range of $20 \% \sim 60 \%$, which is highly correlated with shale clay mineral content and decreases with the increase of well depth. Solute concentration in shale pore fluid is equivalent to $0.2 \mathrm{~mol} / \mathrm{L} \mathrm{NaCl}$ solution. The calculated initial water-saturated membrane efficiency of shale is mainly in the range of $0.4 \sim 0.6$. The minimum is 0.38 ; the maximum is 0.73 ; and the average is 0.48 . Although reservoir interval shale grain density, porosity, initial water saturation, and cation exchange capacity each correlate with depth by their own law, the initial watersaturated membrane efficiency of shale does not change significantly with depth under the comprehensive influence.

With water saturation at $100 \%$, the membrane efficiency of reservoir shale under full water-saturated conditions is calculated, with results being shown in Figure 9. The membrane efficiency of shale under full water-saturated conditions is mainly in the range of $0.05 \sim 0.25$; the minimum is 0.02 , and the maximum is 0.31 . As the calculating values of water saturation are the same (100\%), the membrane efficiency of shale shows a good correlation law with well depth, and the membrane efficiency of shale decreases with the increase of well depth.

5.3. Water-Absorbing Capacity by Chemical Osmosis of Reservoir. The reservoir shale has high membrane efficiency at initial water saturation. Water absorption increases water saturation, causing membrane efficiency to decrease. According to calculation results in Section 5.2, initial water saturation and membrane efficiency of a reservoir interval core under saturated conditions both change regularly as the well depth changes. To characterize the chemical osmotic kinetics of unit pore volume in the process of water absorption, its membrane efficiency is calculated on a range from initial water saturation $s_{\text {wi }}$ to a full water saturated condition. Formula (22) is used to integrate membrane efficiency within the scope of the water adoption saturation and to 


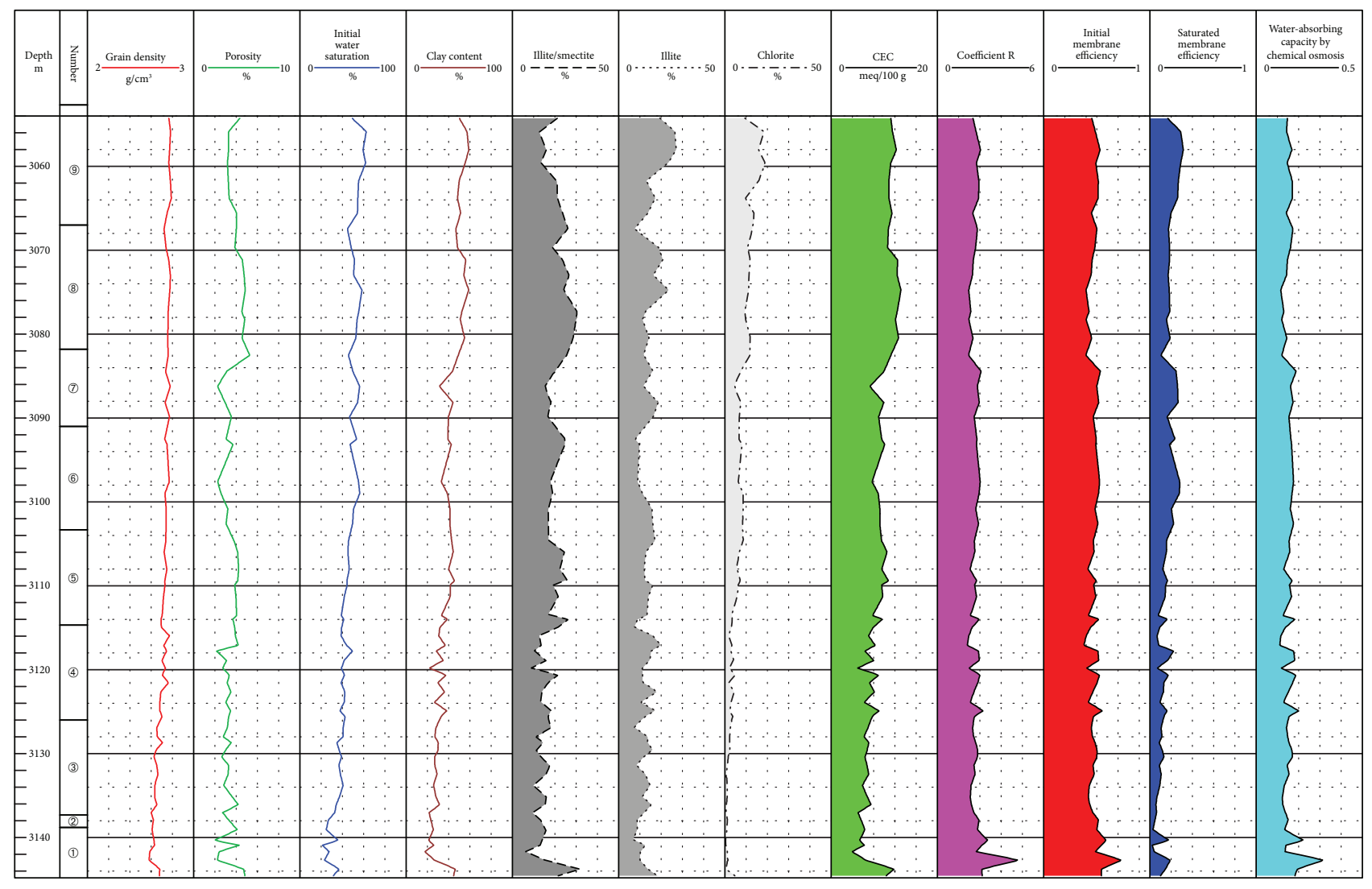

FIgURE 9: Vertical variation within the water-absorbing capacity by chemical osmosis of reservoir interval shale.

characterize water-absorbing capacity by chemical osmosis per unit pore shale.

$$
J=\int_{s_{\mathrm{wi}}}^{100 \%} \sigma \mathrm{d} s_{\mathrm{w}} .
$$

Figure 10 calculates the membrane efficiency of some layers of the reservoir shale by using the average of various physical property parameters. The initial water saturation of each layer shale increases with the number of layers, and the corresponding initial water-saturated membrane efficiency is close. Membrane efficiency decreases with the increase of water saturation, and the membrane efficiency of shale water adoption under saturated conditions increases with the number of layers. However, the integral interval decreases as it moves from initial water saturation to a full water saturated condition, leaving no obvious difference between the integral values of membrane efficiency of water absorption interval.

Longitudinal changes within the water-absorbing capacity by chemical osmosis of reservoir interval shale are shown in Figure 9, and the average value of each layer is shown in Table 3 . The water-absorbing capacity by chemical osmosis per unit pore of shale is mainly within the range of $0.14 \sim 0.17$, the overall difference between the layers being not large. The minimum average value is found in the (8) layer, whereas the average value of (1) layer is the largest. Under the condition that there is not much difference in water-absorbing capacity by chemical osmosis per unit pore of reservoir shale, the water absorption capacity of each layer of shale depends more on its porosity.

\section{Conclusion}

(1) Based on the electrochemistry theory of a clay mineral-water interface, a computational model of the shale membrane efficiency considered water saturation is obtained by using the constitutive equation of multiphase porous media coupling and parameter transformation.

(2) Under unsaturated conditions, the membrane efficiency of shale will decrease with the increase of saturation of water. At high partition coefficient of counterion in the Stern layer, high cation exchange capacity, and low solute concentration in pore fluid, the membrane efficiency of shale is relatively high.

(3) The clay minerals within reservoir shale in Fuling area have a low cation exchange capacity, and the cation exchange capacity of reservoir shale is mainly in the range of $0.06 \sim 0.12 \mathrm{meq} / \mathrm{g}$, which decreases with the increase of well depth.

(4) Calculations of membrane efficiency of Fuling shale show that it is mainly in the range of $0.4 \sim 0.6$ under initial water saturated conditions, and a change trend at each layer is not obvious when observed at different depths. With the increase of water 

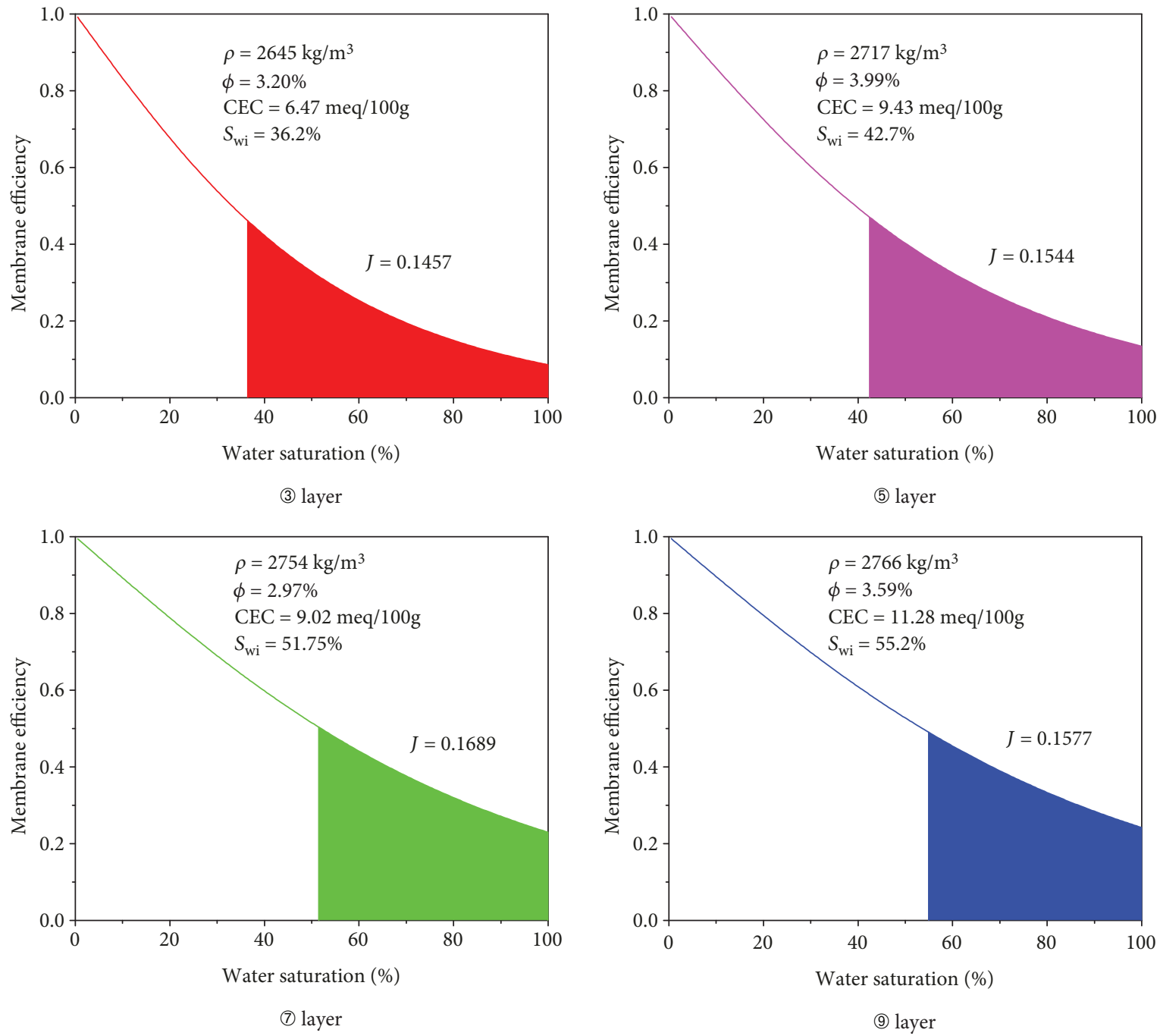

Figure 10: The change in membrane efficiency of reservoir shale throughout the process of water adoption.

TABLE 3: Water-absorbing capacity by chemical osmosis of reservoir shale.

\begin{tabular}{lcccccccc}
\hline Layer & $\begin{array}{c}\text { Grain density } \\
\mathrm{kg} / \mathrm{m}^{3}\end{array}$ & Porosity \% & $\begin{array}{c}\text { Initial water } \\
\text { saturation } \%\end{array}$ & $\begin{array}{c}\text { Clay } \\
\text { content } \%\end{array}$ & $\begin{array}{c}\text { CEC } \\
\text { meq/100 g }\end{array}$ & $\begin{array}{c}\text { Initial membrane } \\
\text { efficiency }\end{array}$ & $\begin{array}{c}\text { Saturated } \\
\text { membrane } \\
\text { efficiency }\end{array}$ & $\begin{array}{c}\text { Water-absorbing } \\
\text { capacity by } \\
\text { chemical osmosis }\end{array}$ \\
\hline (9) & 2766 & 3.59 & 55.20 & 52.26 & 11.28 & 0.4881 & 0.2414 & 0.1577 \\
(8) & 2762 & 4.66 & 52.01 & 53.10 & 12.15 & 0.4314 & 0.1687 & 0.1351 \\
(7) & 2754 & 2.97 & 51.75 & 39.70 & 9.02 & 0.5018 & 0.2296 & 0.1689 \\
(6) & 2742 & 3.09 & 51.14 & 39.83 & 9.14 & 0.4934 & 0.2170 & 0.1654 \\
(5) & 2717 & 3.99 & 42.70 & 39.56 & 9.43 & 0.4679 & 0.1335 & 0.1544 \\
(4) & 2712 & 3.26 & 41.55 & 31.82 & 7.41 & 0.4661 & 0.1239 & 0.0858 \\
(3) & 2645 & 3.20 & 36.20 & 27.29 & 6.47 & 0.4647 & 0.1527 \\
(2) & 2618 & 3.02 & 30.37 & 23.40 & 5.85 & 0.5139 & 0.0731 & 0.1615 \\
(1) & 2631 & 3.69 & 27.85 & 32.20 & 7.75 & 0.5766 & 0.1954 & 0.0922 \\
\hline
\end{tabular}

saturation, the membrane efficiency of shale under full water-saturated conditions is mainly in the range of $0.05 \sim 0.25$, and it decreases with the increase of well depth.
(5) The membrane efficiency of shale should be integrated from the initial water saturation to full water-saturated conditions, and characterize the water-absorbing capacity by chemical osmosis per unit pore of shale. 
The calculated results show that there is no obvious difference in water-absorbing capacity by chemical osmosis per unit pore between each layer at different depths of reservoir interval shale in Fuling area.

\section{Nomenclature}

$C_{\mathrm{f}}$ : Concentration of the solute $\left(\mathrm{mol} \cdot \mathrm{L}^{-1}\right)$

CEC: Cation exchange capacity $\left(\mathrm{C} \cdot \mathrm{kg}^{-1}\right)$

$e: \quad$ Elementary charge $(\mathrm{C})$

$f_{\mathrm{Q}}$ : Fraction of charge located in the Stern layer

$\mathbf{J}_{\mathrm{c}}$ : $\quad$ Macroscopic current density $\left(\mathrm{A} \cdot \mathrm{m}^{-2}\right)$

$\mathbf{J}_{\mathrm{f}}$ : Darcy velocity $\left(\mathrm{m} \cdot \mathrm{s}^{-1}\right)$

$\mathrm{J}_{\mathrm{s}}: \quad$ Macroscopic flux of the salt $\left(\mathrm{mol} \cdot \mathrm{m}^{-2} \cdot \mathrm{s}^{-1}\right)$

$\mathrm{k}$ : Intrinsic permeability of the shale $\left(\mathrm{m}^{2}\right)$

$k_{\mathrm{B}}$ : Boltzmann constant $\left(\mathrm{J} \cdot \mathrm{K}^{-1}\right)$

$K_{\mathrm{s}}$ : Distribution coefficient of the solute in the membrane

$p: \quad$ Intrinsic pore fluid pressure $(\mathrm{Pa})$

$\bar{p}: \quad$ Effective pore fluid pressure $(\mathrm{Pa})$

$Q_{0}$ : Charge density of the surface minerals $\left(\mathrm{C} \cdot \mathrm{m}^{-2}\right)$

$Q_{S}: \quad$ Charge density of the diffuse layer $\left(\mathrm{C} \cdot \mathrm{m}^{-2}\right)$

$Q_{\beta}: \quad$ Charge density of the Stern layer $\left(\mathrm{C} \cdot \mathrm{m}^{-2}\right)$

$\bar{Q}_{\mathrm{V}}$ : $\quad$ Effective charge per unit pore volume of the shale $\left(\mathrm{C} \cdot \mathrm{m}^{-3}\right)$

$Q_{\mathrm{V}}^{0}$ : $\quad$ Total charge density $\left(\mathrm{C} \cdot \mathrm{m}^{-3}\right)$

$\bar{Q}_{\mathrm{V}}^{0}$ : $\quad$ Pore charge density of the water-saturated shale $\left(\mathrm{C} \cdot \mathrm{m}^{-3}\right)$

$R: \quad$ Electrical conductivity dimensionless number

$s_{\mathrm{W}}$ : Water saturation

$S_{\mathrm{nw}}$ : Surface area of the interface between shale gas and water $\left(\mathrm{m}^{2}\right)$

$S_{\text {sw }}$ : Surface area of the interface between shale and water $\left(\mathrm{m}^{2}\right)$

T: $\quad$ Temperature (K)

$T_{\mathrm{e}}^{+}$: Macroscopic Hittorf numbers

$V_{\mathrm{m}}$ : Volume of the pore water in the representative elementary volume $\left(\mathrm{m}^{3}\right)$

$\beta_{ \pm}$: $\quad$ Mobilities of the cation and anion in water $\left(\mathrm{m}^{2} \cdot \mathrm{s}^{-1} \cdot \mathrm{V}^{-1}\right)$

$\rho_{\mathrm{g}}: \quad$ Bulk density of the grains $\left(\mathrm{kg} \cdot \mathrm{m}^{-3}\right)$

$\theta: \quad$ Water content

$\phi$ : $\quad$ Porosity of the shale

$\mu_{\mathrm{f}}: \quad$ Chemical potential of the salt $(\mathrm{J})$

$\psi: \quad$ Electrical potential (V)

$\pi: \quad$ Osmotic pressure $(\mathrm{Pa})$

$\sigma: \quad$ Membrane efficiency

$\sigma_{\mathrm{e}}: \quad$ Electrical conductivity of the shale $\left(\mathrm{S} \cdot \mathrm{m}^{-1}\right.$ )

$\sigma_{\mathrm{e}}^{ \pm}$: Contribution of ions to the total DC-electric conductivity $\left(\mathrm{S} \cdot \mathrm{m}^{-1}\right)$.

\section{Data Availability}

The data used to support the findings of this study are available from the corresponding author upon request.

\section{Conflicts of Interest}

The authors declare that they have no conflicts of interest.

\section{Acknowledgments}

This research was supported by the National Natural Science Foundation of China (Major Program 51490652), Research Foundation of China University of Petroleum-Beijing at Karamay (RCYJ2016B-01-001), and National Science and Technology Major Project (2017ZX05039-004). The authors also would like to thank Sinopec Chongqing Fuling Shale Gas Exploration and Development Co. Ltd., who kindly provided the in-site shale samples for the experimental tests.

\section{References}

[1] R. Rezaee, Fundamentals of Gas Shale Reservoirs, John Wiley \& Sons, 2015.

[2] M. A. Sayed, G. A. Al-Muntasheri, and F. Liang, "Development of shale reservoirs: knowledge gained from developments in North America," Journal of Petroleum Science and Engineering, vol. 157, pp. 164-186, 2017.

[3] H. Singh, "A critical review of water uptake by shales," Journal of Natural Gas Science and Engineering, vol. 34, pp. 751-766, 2016.

[4] J. Wang and S. S. Rahman, "Investigation of water leakoff considering the component variation and gas entrapment in shale during hydraulic-fracturing stimulation," SPE Reservoir Evaluation \& Engineering, vol. 19, no. 3, pp. 511-519, 2016.

[5] Z. Zhou, H. Abass, X. Li, D. Bearinger, and W. Frank, "Mechanisms of imbibition during hydraulic fracturing in shale formations," Journal of Petroleum Science and Engineering, vol. 141, pp. 125-132, 2016.

[6] A. J. Staverman, "Non-equilibrium thermodynamics of membrane processes," Transactions of the Faraday Society, vol. 48 , pp. 176-185, 1952.

[7] B. D. Cey, S. L. Barbour, and M. J. Hendry, "Osmotic flow through a Cretaceous clay in southern Saskatchewan, Canada," Canadian Geotechnical Journal, vol. 38, no. 5, pp. 1025-1033, 2001.

[8] M. Takeda, T. Hiratsuka, M. Manaka, S. Finsterle, and K. Ito, "Experimental examination of the relationships among chemico-osmotic, hydraulic, and diffusion parameters of Wakkanai mudstones," Journal of Geophysical Research: Solid Earth, vol. 119, no. 5, pp. 4178-4201, 2014.

[9] I. R. Kivi, M. J. Ameri, and A. Ghassemi, "Experimental and numerical study of membrane properties and pore pressure transmission of Ghom shale," Measurement, vol. 91, pp. 93100, 2016.

[10] I. Medved and R. Černý, "Osmosis in porous media: a review of recent studies," Microporous and Mesoporous Materials, vol. 170, pp. 299-317, 2013.

[11] A. Katchalsky and P. F. Curran, Nonequilibrium Thermodynamics in Biophysics, Harvard University Press, Cambridge, MA, USA, 1965.

[12] I. W. Marine and S. J. Fritz, "Osmotic model to explain anomalous hydraulic heads," Water Resources Research, vol. 17, no. 1, pp. 73-82, 1981.

[13] S. J. Fritz and I. W. Marine, "Experimental support for a predictive osmotic model of clay membranes," Geochimica et Cosmochimica Acta, vol. 47, no. 8, pp. 1515-1522, 1983.

[14] W. D. Kemper and J. B. Rollins, "Osmotic efficiency coefficients across compacted clays," Soil Science Society of America Journal, vol. 30, no. 5, pp. 529-534, 1966. 
[15] J. Letey, W. D. Kemper, and L. Noonan, "The effect of osmotic pressure gradients on water movement in unsaturated soil," Soil Science Society of America Journal, vol. 33, no. 1, pp. 15$18,1969$.

[16] W. D. Kemper and J. P. Quirk, "Ion mobilities and electric charge of external clay surfaces inferred from potential differences and osmotic flow," Soil Science Society of America Journal, vol. 36, no. 3, pp. 426-433, 1972.

[17] E. Bresler, "Anion exclusion and coupling effects in nonsteady transport through unsaturated soils: I. Theory," Soil Science Society of America Journal, vol. 37, no. 5, pp. 663-669, 1973.

[18] S. Bader, Osmosis in Groundwater: Chemical and Electrical Extensions to Darcy's law [Ph.D. thesis], TU Delft, Delft University of Technology, 2005.

[19] C. E. Neuzil, "Osmotic generation of 'anomalous' fluid pressures in geological environments," Nature, vol. 403, no. 6766, pp. 182-184, 2000.

[20] A. M. Garavito, H. Kooi, and C. E. Neuzil, "Numerical modeling of a long-term in situ chemical osmosis experiment in the Pierre Shale, South Dakota," Advances in Water Resources, vol. 29, no. 3, pp. 481-492, 2006.

[21] B. Loret, A. Gajo, and F. M. F. Simões, "A note on the dissipation due to generalized diffusion with electro-chemomechanical couplings in heteroionic clays," European Journal of Mechanics - A/Solids, vol. 23, no. 5, pp. 763-782, 2004.

[22] A. M. Garavito, P. De Cannière, and H. Kooi, "In situ chemical osmosis experiment in the boom clay at the Mol underground research laboratory," Physics and Chemistry of the Earth, Parts A/B/C, vol. 32, no. 1-7, pp. 421-433, 2007.

[23] S. Baechler, J. Croisé, and S. Altmann, "Modelling coupled chemico-osmotic and advective-diffusive transport of nitrate salts in the Callovo-Oxfordian clay," Advances in Water Resources, vol. 49, pp. 76-85, 2012.

[24] P. Leroy and A. Revil, "A triple-layer model of the surface electrochemical properties of clay minerals," Journal of Colloid and Interface Science, vol. 270, no. 2, pp. 371-380, 2004.

[25] A. Revil, P. Leroy, and K. Titov, "Characterization of transport properties of argillaceous sediments: application to the Callovo-Oxfordian argillite," Journal of Geophysical Research, vol. 110, no. B6, 2005.

[26] J. Gonçalvès, P. Rousseau-Gueutin, and A. Revil, "Introducing interacting diffuse layers in TLM calculations: a reappraisal of the influence of the pore size on the swelling pressure and the osmotic efficiency of compacted bentonites," Journal of Colloid and Interface Science, vol. 316, no. 1, pp. 92-99, 2007.

[27] D. Jougnot, A. Revil, N. Lu, and A. Wayllace, "Transport properties of the Callovo-Oxfordian clay rock under partially saturated conditions," Water Resources Research, vol. 46, no. 8, 2010.

[28] A. Revil, "Transport of water and ions in partially watersaturated porous media. Part 1. Constitutive equations," Advances in Water Resources, vol. 103, pp. 119-138, 2017.

[29] A. Meunier, Clays, Springer Science \& Business Media, 2005.

[30] A. H. D. Cheng, Poroelasticity, Springer, Cham, Switzerland, 2016.

[31] P. Leroy and A. Revil, "A mechanistic model for the spectral induced polarization of clay materials," Journal of Geophysical Research, vol. 114, no. B10, 2009.

[32] A. Revil, "Spectral induced polarization of shaly sands: influence of the electrical double layer," Water Resources Research, vol. 48 , no. $2,2012$.
[33] Y. X. Lin, S. Y. Gao, and Y. J. Zeng, "Study of shale microfracture propagation based on tomographic technique," Scientia Sinica Physica, Mechanica \& Astronomica, vol. 47, no. 11, article 114606, 2017.

[34] W. F. Woodruff and A. Revil, "CEC-normalized clay-water sorption isotherm," Water Resources Research, vol. 47, no. 11, 2011.

[35] A. Rabaute, A. Revil, and E. Brosse, "In situ mineralogy and permeability logs from downhole measurements: application to a case study in chlorite-coated sandstones," Journal of Geophysical Research: Solid Earth, vol. 108, no. B9, 2003. 

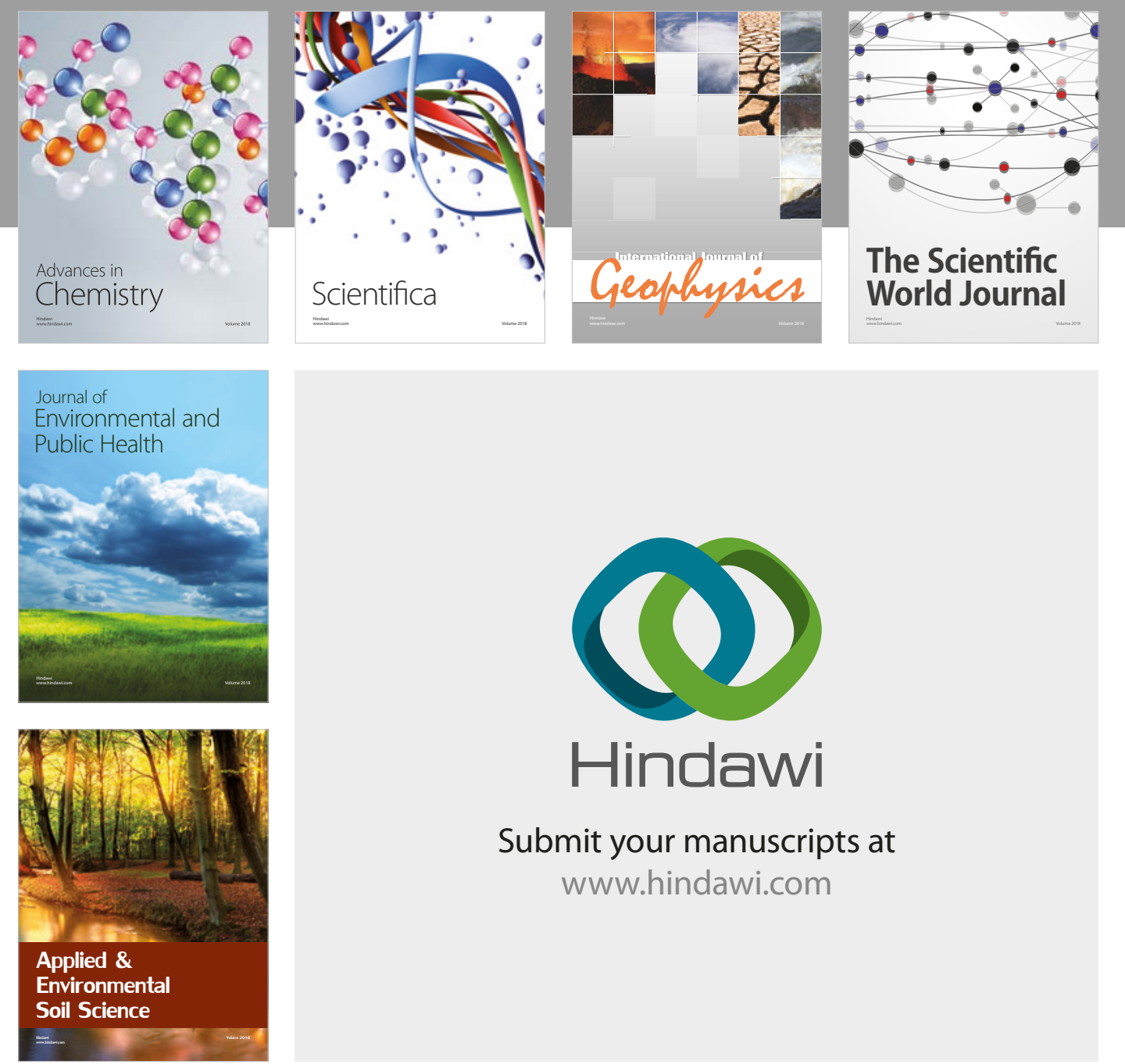

The Scientific

\section{World Journal}
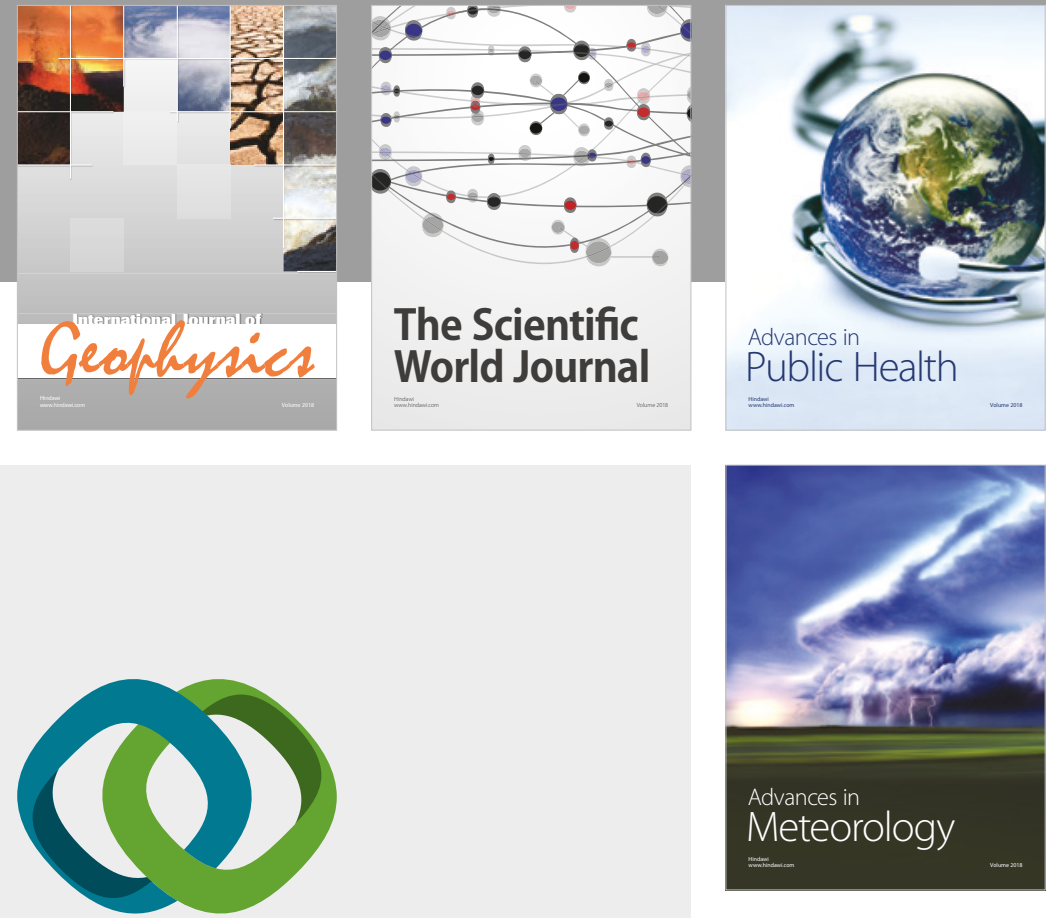

Advan

Public Health

\section{Hindawi}

Submit your manuscripts at

www.hindawi.com
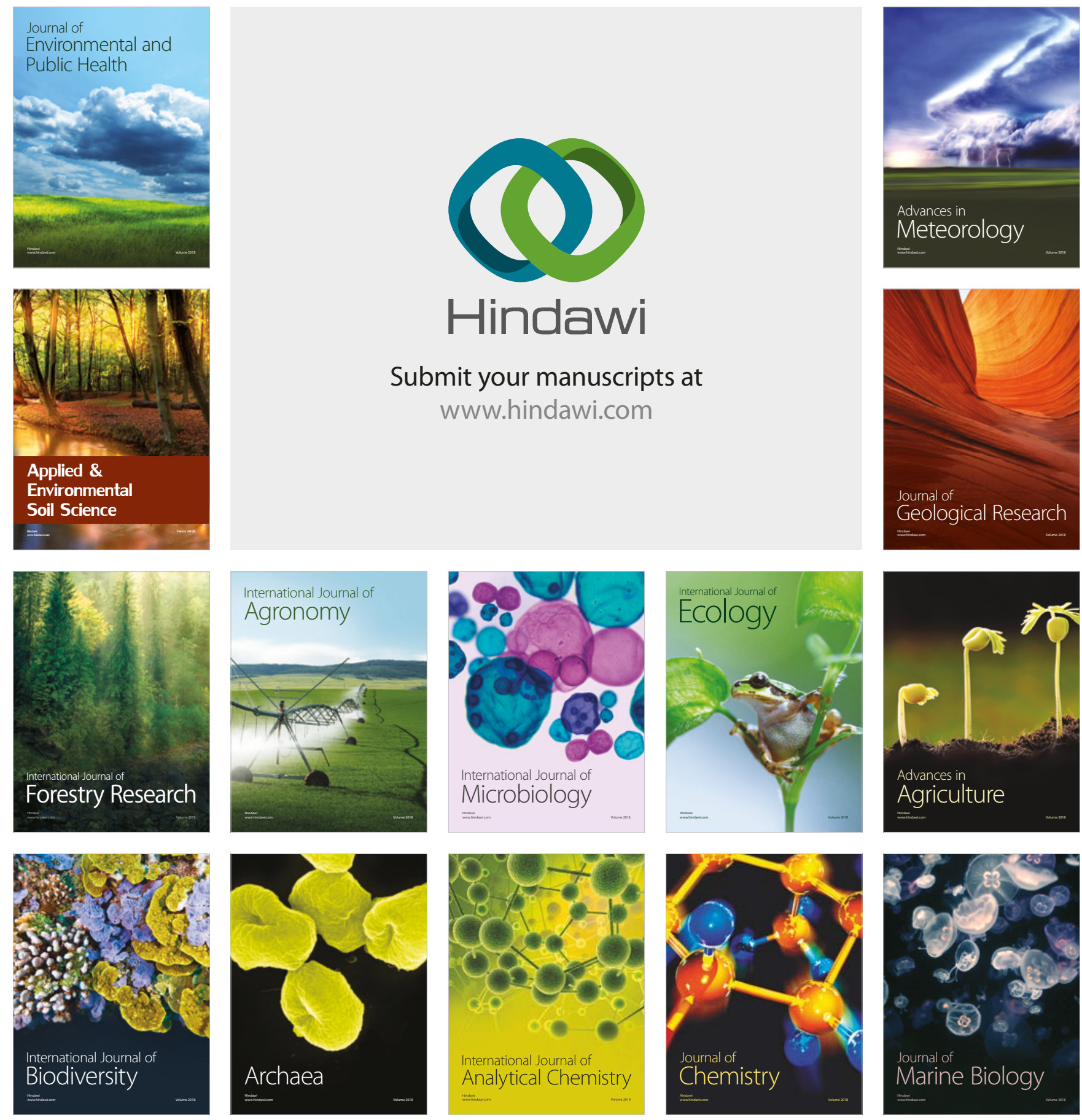